\title{
Migración retornada y juventud indígena (Zacualpa, Guatemala)
}

Ricardo Falla, sj.

Plataforma indígena de la Compañía de Jesús, Centroamérica.

En este artículo resumo una investigación que acaba de ser publicada en forma de libro sobre la juventud indígena y la migración retornada en Zacualpa, Guatemala. ${ }^{1}$ De entrada advierto que los resultados de esta investigación reflejan la situación de principios de 2007. Ya se estaba enrareciendo entonces el ambiente con deportaciones masivas en los Estados Unidos, como fue la de las fábricas Swift el 12 de diciembre de 2006. Pero el repunte del número de deportaciones de 2007 no se había sentido tan fuertemente. Tampoco la depresión económica en los Estados Unidos se había dejado sentir, como a fines de 2007 y principios de

\section{8.}

Por un lado, el cambio de coyuntura hace que los resultados de esta investigación no correspondan exactamente al momento actual. No es un artículo periodístico. Pero, por otro lado, ese cambio hace que el enfoque de la migración retornada se haga cada vez más importante, puesto que las dificultades para la población migrante en Estados Unidos, tanto de tipo laboral (desempleo) como político (amenazas de deportación), incidirán en que más compatriotas centroamericanos decidan regresar a sus tierras de origen.

\section{Guerra, huída al interior y migración transnacional}

Zacualpa es un municipio de unos 30 mil habitantes (ahora), casi todos ellos $k$ 'iche', del departamento de El Quiché, Guatemala. Es uno de los tantos pueblos que durante el conflicto interno armado sufrieron la represión más horrenda de parte del ejército de Guatemala. Allí el ejército ocupó el convento y puso su cuartel de operaciones de 1981 a 1986. Quedan vestigios de los lugares de tortura -convertidos ahora en capillascomo los garfios donde se colgaba a las víctimas o el pozo donde se enterraba a los asesinados. Zacualpa fue un lugar donde el gobierno y el ejército de entonces practicaron sistemáticamente el genocidio, como lo ha comprobado la Comisión de Esclarecimiento Histórico que escogió ese municipio como prototipo del genocidio en la etnia $k$ 'iche'.

La brutal represión de esos años -unos 1,500 muertos en un lugar de cerca de 20 mil habitantes entonces- fue como una bomba que hizo que la gente migrara en busca de refugio a las fincas de la costa y la bocacosta de Guatemala y a la ciudad de Guatemala. La distancia de la frontera mexicana les impidió correr en masa a refugiarse a México. La migración estacional a las fincas de café, iniciada desde fines del siglo XIX, y la migración estacional a las fincas de caña (ingenios) y de algodón se convirtió entonces en migración permanente de varios años. 
No fue sino hasta principios de la década de los 90, cuando la migración a los Estados Unidos se convirtió en una opción migratoria masiva. Para esos años ya el país comenzaba a salir de la oscuridad de la guerra, se iniciaba de nuevo el movimiento económico en las áreas reprimidas y la movilización geográfica era más libre. La población refugiada en la bocacosta, en la costa y en la ciudad se atrevió, entonces, a retornar poco a poco a su pueblo de origen por pequeños núcleos familiares y el sueño americano empezó a obsesionar con cada vez más fuerza a la juventud que buscaba el dólar frente a una moneda nacional que se iba depreciando. El cambio del quetzal pasó de 1 por 1 a 7 por $1 .^{2}$ Ese deslizamiento rápido de la moneda tuvo un efecto de boom en esa década y en la actualidad se puede estimar un cálculo conservador de una población de 5,000 personas en el norte para el total de 30 mil habitantes de Zacualpa.

\section{Mirada hacia el norte}

Ante este movimiento de personas y pueblos que migran hacia los Estados Unidos, la literatura de las ciencias sociales se ha enfocado casi únicamente en una dirección: la migración hacia el norte. Este enfoque ha abarcado la decisión para emprender el viaje, la institución explotadora de los intermediarios, el viaje mismo, las violaciones a los derechos de los migrantes en el país de paso, la adaptación en el país de llegada, la formación de comunidades transnacionales, etc. La mirada de la investigación se nos ha ido hacia el norte y las personas investigadoras se han ido también a veces al norte para comprender cómo viven y trabajan allá los connacionales.

Como los efectos de esta salida se sufren aquí, también la literatura se ha ido llenando de estudios sobre el impacto económico, social, político y cultural de la emigración, en el lugar de origen. Ordinariamente estos estudios tienen una visión peyorativa del fenómeno, debido, en parte, a que los informantes son los que no han viajado y defienden los valores tradicionales. Dentro de estos estudios toma especial relieve el efecto de la remesa. Aparece la remesa constantemente en estudios micro de comunidades y en estudios cuantitativos a nivel nacional, ya que las remesas son dentro del PIB el renglón más importante, por encima del turismo, del café, de la industria... A la vez, se prioriza el aspecto cuantitativo del proceso de la migración: la cantidad en dólares de la remesa por mes y por año.

Luego se ha ampliado el concepto de remesa económica al de remesa cultural, como son hábitos, valores, formas de pensar... Algunos autores critican este préstamo del concepto económico porque los hábitos, valores, formas de pensar, etc. no son comparables con el dinero y porque la facilidad de la cuantificación no se puede trasladar de la misma manera de lo económico a lo cultural. El Banco de Guatemala cuantifica las remesas cada mes, pero ¿cómo cuantificar el cambio de valores solidarios a valores individualistas?

En este artículo proponemos, siguiendo a autores que han estudiado la migración en las islas Caribe, la necesidad de enfocar el fenómeno de la migración desde una perspectiva distinta: desde el retorno (Conway y Potter 2006). El cambio de perspectiva lleva a un cambio de método, dándole más campo a la capacidad transformadora (agency) de los sujetos. En este sentido, se insiste en no ver los valores, pensamientos, hábitos... en abstracto, desligados de los sujetos activos, sino desde el análisis del sujeto. Aunque todo tiene su riesgo, podríamos 
decir que no nos interesa tanto la remesa económica, ni la remesa social y cultural, cuanto "la remesa viva", que no es "remesa" porque nadie la mandó, sino que la persona misma decidió retornar. Aun en el caso del deportado que fue forzado a volver, nos interesa seguir todo el proceso activo del sujeto que intenta quedarse, se frustra, escoge alternativas que le presentan los abogados y tiene que decidir al volver si emprende de nuevo el viaje o se queda en su tierra.

El enfoque sobre el sujeto del retorno nos da una valoración distinta, tanto de la migración a los Estados Unidos y de la estancia allá, como del retorno, la adaptación a la comunidad de origen y los cambios de ésta necesarios para desarrollarse. Aunque no negamos el valor de la perspectiva de la persona que no ha migrado al norte, es necesario atender a la persona retornada: conoce el aquí y el allá.

\section{Retorno de la perspectiva}

¿Cómo llegamos a este cambio de perspectiva? No soy un especialista de la migración, ni conozco toda la literatura que se ha escrito en el área guatemalteca, centroamericana, latinoamericana y mundial. Son toneladas de libros y artículos. No llegué a este cambio de perspectiva a través del estudio bibliográfico, sino a través del trabajo de campo que me puso en contacto con las personas en esa comunidad que expulsa migrantes. Después de la recolección de mucho material de todo tipo, me pregunté por dónde comenzar el análisis. El trabajo de campo había sido orientado al tema todavía muy amplio de juventud y migración. Entonces, en vez de hacer una monografía de temas superficialmente conectados, comencé a analizar las entrevistas más ricas, más articuladas, más inmediatas del fenómeno migratorio. ¿Quiénes las daban? Eran jóvenes que conocían la migración de primera mano porque ellos mismos habían sido migrantes. La riqueza de la entrevista, entonces, me llevó al cambio de perspectiva. El análisis de caso se constituyó en análisis de un sujeto vivo migrante retornado.

Había entrevistado a tres jóvenes varones, de los cuales uno explicaba más la ida a los Estados Unidos, otro la estancia allá y un tercero el retorno y la reintegración en la comunidad. Volví al terreno, más orientado, para buscar a la joven retornada que me diera su punto de vista como mujer. Su relato fue tan rico que con ella pude cubrir las mismas tres fases, la ida, la estancia, y el retorno y reintegración.

Fue en este momento cuando acudí a José Luis Rocha que conoce más del tema de la migración dentro de la red del SJM-CA ${ }^{3}$. Él me orientó a la literatura actual sobre la migración retornada del Caribe. Allí fue donde me di cuenta que dentro de la literatura social esta perspectiva abría un capítulo todavía poco explorado. ${ }^{4}$ Los autores atribuyen este rezago a diversos factores: las personas retornadas eran los viejos y retirados que ya no tienen capacidad de transformación, se decía; los que retornan son una despreciable minoría frente a los que se van... Los autores explican las innumerables formas de capacidad transformadora de estos sujetos que han ido creciendo en número. Las famosas remesas económicas, tan atendidas por los economistas, en muchos casos son manejadas por las personas retornadas. 
Luego me fui enfocando en la capacidad transformadora de estas personas. Reconozco que esta investigación es muy inicial. Hay más formas de analizar el aspecto transformador de los sujetos que no es sólo a través de la narración de ellos mismos. Me centré en algunos hechos: en el caso de un joven, cómo logra introducir a nivel de toda la parroquia (centro y aldeas) los instrumentos musicales electrónicos en contra de la tradición de los mayores, y en el caso de la joven, cómo logra desarticular la mara de su aldea.

El estudio se inició como un estudio de la juventud. En el proceso de análisis hubo un desplazamiento del objeto material. De la juventud que acaba de atravesar la adolescencia me desplacé a la juventud adulta, la que ya tiene un compromiso en la vida. Los cuatro tienen hijos pequeños y están casados. Pero ellos y ella mantienen la experiencia juvenil fresca. Una ampliación del estudio será comparar juventud adulta con "juventud joven", por un lado, y por otro, con personas adultas retornadas.

En todo el estudio, hay que advertir, ha habido un esfuerzo metodológico de neutralidad. Nos ha interesado detectar la capacidad transformadora de la juventud adulta retornada, ya sea para introducir cambios alienantes, como para introducir cambios liberadores, suponiendo, cosa que puede ser cuestionada, que esa capacidad es dúctil. El esfuerzo por la neutralidad no cancela, sin embargo, una opción de fondo por la solidaridad y los cambios en esa dirección. Por eso, al final del estudio, sin poder entrar en más detalle, terminamos con una frase exclamativa: iHace falta formación política! La hipótesis a la que llegamos como conclusión es que una formación política seria podría abrir la mente y conducir la acción hacia metas solidarias, y que hay que aprovechar a la población retornada que tiene experiencia de la globalización para fomentar cambios hacia la justicia en esas comunidades atenazadas por estructuras de opresión, desde las relaciones económicas, hasta las culturales, como son el racismo y la opresión de género.

\section{Arco iris del retorno}

Desmenucemos los tipos de retorno para precisar más el enfoque. Según la organización del retorno nos encontramos con un arco iris de formas. La primera, que conocemos más de cerca y que sí ha sido objeto de algunos estudios en Guatemala, es la colectiva, como fue el retorno de los refugiados desde México en diversas oleadas. Hubo retorno organizado por el gobierno en un plan de contrainsurgencia (repatriados, se les llamaba), y luego, retorno organizado por los mismos refugiados desde los campamentos con el apoyo de la cooperación internacional (retornados, se llamaron). En nuestro estudio no nos hemos fijado en esta forma de retorno. La hemos tocado en un estudio de la Juventud del Ixcán, donde la población retornada se contrastó con la resistencia. ${ }^{5}$

Una segunda forma de organización del retorno es la individual. Por ejemplo, la de estudiantes que salen becados al exterior; algunos se quedan allá, otros retornan. Nosotros mismos hemos pasado por esta experiencia. Jamás se nos ocurrió quedarnos fuera, porque habíamos ido con una meta de tiempo clara, un objetivo de aprovechar esos estudios para trabajar aquí, teníamos una matriz organizativa que nos apoyaba afuera, nos exigía volver y nos daba trabajo aquí. Volvimos con cierta capacidad transformadora, la cual se puso de manifiesto al ver cómo nos apoyábamos al retornar acá, aunque no formáramos una organización formal para ello. Tampoco en esta forma nos estamos fijando aquí. 
Una tercera, que es la que estudiamos aquí, es la que podríamos llamar organización en red y es la típica de la globalización. ${ }^{6}$ Los migrantes, al viajar a Estados Unidos están sostenidos por una red, completamente informal, de parientes, amigos, paisanos, gente de la misma etnia..., una red que se cruza y se forma de muchas redes, porque la de parientes no es la misma que la de amistades. Esta red es la que tiene como referencia a la comunidad transnacional, la cual no necesariamente consiste en un grupo compacto de originarios de la misma comunidad, sino de una red de redes con una red más fuerte que es la de paisanos. Esta red es la que sirve para la vuelta del migrante, no porque se regrese de la misma forma como se fue (se fue mojado, vuelve en avión), sino porque, si no estuviera en la red, no volvería, así como si no estuviera en la red, no hubiera podido viajar al norte. Esta tercera es la que hemos estudiado aquí. Toca el trabajo... no el estudio. Son redes para conseguir trabajo y residencia... no para obtener becas. Por supuesto, es un estudio inicial y hace falta analizar más la forma organizativa de esas redes.

También según la voluntariedad del retorno encontramos todo un arco iris. Usamos la metáfora del arco iris porque entre una forma y la otra no hay una separación completa. Un color se cambia en otro, el amarillo en verde, y sin embargo el amarillo no es el verde.

Una primera forma es el retorno voluntario. En este nos hemos fijado aquí. Por ser voluntario, el tema de la identidad está muy presente. Nos hemos fijado en los sujetos que activamente han decidido volver a la comunidad de origen y nos hemos fijado en los procesos de cambio de identidad de la que se generan las decisiones. Ordinariamente se dan crisis profundas.

Una segunda es el retorno forzado/voluntario. Puede ser por la economía o por otras razones, como el ambiente de zozobra que se vive en el norte. En el caso de la economía, se trata de sopesar en la balanza: ¿dónde estoy mejor? No es solamente el cálculo cuantitativo en dinero lo que se pone en la balanza, dónde gano más. Sino el valorativo de lo que gano, lo que trabajo, las condiciones de trabajo, las posibilidades del descanso, la situación de esclavitud... sólo trabajar versus trabajar cuando quiero.

Una tercera es el retorno forzado, especialmente por las autoridades, léase en el caso norteamericano, las de la ICE (Immigration and Customs Enforcement) que deportan al migrante, hombre o mujer.

Hay diversos tipos de retorno según el tiempo previsto de permanencia en el lugar de origen. Éste puede ser definitivo, cuando el migrante vuelve para no regresar al norte; temporal, si vuelve de visita, por ejemplo de paseo, durante unos meses; o pendular, si su vuelta tiene un patrón de permanencia por un tiempo en el lugar de origen y permanencia por otro tiempo en el norte. Aquí nos hemos centrado en el retorno definitivo.

Hay que distinguir la identidad (las raíces) de las personas del tiempo calculado en meses o años. En el primer caso, las raíces están en el lugar de origen, en el segundo, en el norte y en el tercero, en ambos lugares, con dos identidades o con una identidad fluida o híbrida. Evidentemente, si hay facilidad de movimiento de un lugar a otro, por ejemplo, a través de visa, el retorno pendular es posible y la identidad doble, fluida o como se la quiera llamar, es una realidad casi diaria. Si existe un desierto que hay que atravesar, el penduleo se hace difícil y la identidad supone una opción. 
Hemos visto el penduleo en otros movimientos migratorios, también del tipo globalizado con la organización de red, que no se dan de Guatemala a Estados Unidos. Por ejemplo, la juventud que nació en México en campamentos de refugiados y que migró colectivamente al Ixcán guatemalteco, pendulea entre Guatemala y México y se siente de ambas patrias a la vez. La doble nacionalidad jurídica, que no es lo mismo que la identidad nacional, le facilita ese movimiento. Por la facilidad del traslado de un país al otro (sin un desierto y una muralla en medio) esta situación suponemos que tiene semejanza con la de nicaragüenses que migran a Costa Rica y retornan y vuelven a migrar y vuelven a retornar.

Estos tipos de retorno según tiempo también se sitúan en un arco iris porque un tipo se encuentra contiguo al otro como el amarillo al verde, pero no son iguales.

En el estudio que venimos realizando, sin embargo, nos hemos centrado en el retorno definitivo, aunque muchas veces nos engañamos cuando la gente dice que ya volvió para quedarse y a los meses desaparece y nos enteramos que se fue al norte. Los resultados del análisis de la identidad dependen de las circunstancias. No se puede decir que así se da en todas partes.

\section{Matriz del retorno: la comunidad transnacional}

Hemos dicho arriba que las redes de una comunidad transnacional permiten la migración en ambas direcciones. También al revés, la migración en ambas direcciones fortalece a esa comunidad transnacional. Pero no se puede hablar de un solo tipo de comunidad transnacional. La flexibilidad de los conceptos depende de las circunstancias y del análisis. Es peligroso, no sólo conceptualmente, sino para la práctica pensar en conceptos unívocos.

Hay una tendencia reciente a enfatizar la continuidad de identidades en la comunidad transnacional. Esta tendencia enfatiza el hecho de que las fronteras de los países y de las comunidades se han extendido sorpresivamente dentro de los Estados Unidos. Guatemala ya no está limitada por el Suchiate. Guatemala es mucho más extensa, Guatemala está en Nueva York. Esta tendencia resalta la comunidad de identidad guatemalteca -no estamos hablando de nacionalidad jurídica-, como si los guatemaltecos que ya optaron por quedarse en el norte fueran igualmente guatemaltecos que los que se quedaron en Guatemala. Si dentro de la identidad existe la perspectiva del que la tiene y la del que la observa, esta tendencia es más propia de los que se dicen guatemaltecos y viven en el extranjero y desde allá romantizan a la patria, pero no vuelven. No vuelven, aunque también dentro de ese romantizamiento esté presente la ideología del retorno: "volveré”. Ideología, porque nunca vuelven. Es una manera de ver la realidad que enfatiza la continuidad entre los dos polos de la comunidad transnacional.

Hay otra tendencia que marca la ruptura de identidades en la comunidad transnacional. Esta es más propia de la perspectiva de los que se quedan en el país de origen y de los cientistas sociales que no se han dejado invadir por el fenómeno nuevo de la migración y sus identidades. Es una perspectiva más tradicional. Según ésta, los guatemaltecos en el extranjero, aunque se digan guatemaltecos, ya no lo son. Nacieron en Guatemala, pero perdieron "la mente”, el no’jib’al se diría en $k$ ’iche’. Se parecen a los indígenas que dicen 
que son indígenas pero ya no piensan como indígenas porque se integraron en estructuras de poder o de convivencia social de riqueza. Ellos dirán que son indígenas, pero quienes los miran de fuera piensan y dicen que ya son ladinos.

Finalmente, hay otra tendencia más dialéctica que admite que hay continuidad pero a la vez hay ruptura. La hemos encontrado entre los migrantes retornados, hombres o mujeres, que han vivido ambas experiencias, la de enraizamiento en el norte y la de la vuelta. Pueden situarse en ambas perspectivas. Sin embargo, debido a que el retorno ha sido voluntario (en esta suposición de estudio estamos, ya lo dijimos) resalta la ruptura en la dialéctica. Desde lejos aprendieron a valorar su patria y su comunidad, pero no se quedaron añorándola, sino que tomaron la determinación de volver, aunque ese retorno les haya costado sangre por haber dejado, por ejemplo, a una mujer que amaban. Las crisis de identidad vividas por los retornados voluntarios son expresión de esa dialéctica, dentro de la cual privó la ruptura sobre la continuidad.

Los casos estudiados no nos dan para saber cómo se darán estas perspectivas en aquellos retornados en penduleo. Es posible -lo imaginamos solamente- que en ellos la dialéctica se viva sin que un extremo de ella prive sobre el otro. En cuyo caso se nos abre el horizonte a la investigación de una identidad más profunda que la nacional o que la de la comunidad de un lado o del otro, una identidad independiente del lugar, que se define por la misión que siente la persona en su vida. Entonces también la identidad se entiende no sólo como el contraste del yo y del otro, sino primariamente como el sentido de la vida. ${ }^{7}$

\section{Migración y retorno indígena}

Los indígenas de Guatemala heredaron de sus abuelos míticos y de sus pueblos históricos la capacidad de explorar nuevos terrenos y sociedades. Su cultura siempre ha estado abierta a la migración, a veces con retorno, a veces sin él.

En este estudio hemos enfocado la migración de la juventud indígena. No partimos del estudio de la migración para estudiar la juventud en general, sino al revés, de la juventud indígena al de la migración. Esa fue la opción de una serie de estudios, conocer el impacto de la globalización en una juventud que no se estudia ni se suele mencionar al hablar de las costumbres y los cambios de la juventud de las ciudades y de las ciudades de culturas occidentales.

Sin embargo, habiendo plantado nuestra tienda de investigación en el campo de Zacualpa, hemos tenido que contrastar a la juventud indígena con la no indígena (ladina), ya que ese municipio, especialmente en su casco urbano, tiene una constitución biétnica según la cual tradicionalmente la sociedad ladina ha sido dominante y explotadora -cosa que actualmente va cambiando- pues tras la guerra, las alianzas del indígena se vincularon más con la revolución y las de la población ladina con el ejército. 


\section{Resultados de la investigación}

Cuando hacemos una investigación cualitativa que se basa en el análisis de casos, las conclusiones a las que llegamos son siempre hipótesis. Necesitan sustento numérico para comprobarse. Son resultados provisionales que pueden no satisfacer, porque siempre podemos encontrar casos que contradicen la hipótesis.

Además, el resultado se va logrando en el curso del análisis al comprender la interconexión de factores que sorprenden. Por eso, este artículo (resumen) se queda corto ante el libro. Carece de la riqueza de los testimonios, del avance dinámico del análisis y de esa sorpresa que el autor comunica al lector cuando encuentra algo nuevo. Por eso, si en este artículo mencionamos resultados lo hacemos con esa insatisfacción de que al trasladar al abstracto los procesos de los sujetos se empobrecen enormemente.

\section{La base del empoderamiento}

Nos hemos preguntado desde el principio qué capacidad de transformación hemos encontrado que tiene esta juventud adulta en un pueblo indígena de Guatemala, como Zacualpa. ¿Pretende hacer de Guatemala otro Estados Unidos? ¿Se olvida de la gente pobre a su alrededor cuando viene cargada de televisores, tal vez, en un carro de segunda? ¿Hacia dónde se inclina?

Lo primero que hemos observado en ella es que esa juventud retornada no tiene identidad de retornada. Este descubrimiento es contrario a la suposición con la que empezamos, pues estábamos acostumbrados a la población de los retornos colectivos que se marcaban con una identidad muy distinta frente a las poblaciones que no habían salido al refugio y se habían quedado resistiendo en las montañas de Guatemala. La juventud retornada en redes de globalización no tiene identidad de retornada, porque al optar por el retorno opta por ser de la comunidad de origen y de identificarse con ella. La opción del retorno la funde en su identidad con la identidad de origen, con su etnia, con el país del que ella salió. Recordemos que estamos hablando del retorno voluntario, muchas veces decidido después de crisis profundas de autovaloración y de valoración de los dos países.

Sin embargo, en el curso del análisis fuimos descubriendo que esa juventud posee una especie de "aura" que consiste en la conciencia de ella de que estuvo en el norte y en la conciencia de todos los que la ven en la comunidad de que es una retornada con experiencia de Estados Unidos. Esa marca que tiene no se convierte en identidad, pero es un elemento que se tiene en consideración cuando se planifican acciones en la comunidad por parte de otras personas. Tratan de que la persona retornada de los Estados Unidos se integre para que le dé peso al plan que se piensa. Por ejemplo, la invitan al llegar para ganarla.

La experiencia del norte se expresa en temas recurrentes que encontramos en casi todas las historias de los migrantes. Esta juventud retornada cuenta cómo decidió viajar al norte, cómo pasó el desierto, cómo se acomodó allá los primeros días, qué trabajos hizo al llegar, cómo fue subiendo en la escala de salarios, qué escalas de discriminación encontró, cómo sintió que le imponían una identidad de ilegal, cómo comenzó a enviar remesas a su familia, 
qué crisis pasó con la pareja que dejó en la comunidad, en qué vicios cayó, etc., etc. Hay historias más propias de hombres e historias más propias de mujeres. Pero todas ellas son el resumen de la experiencia del norte.

Estas historias son comunes a las personas migrantes que se encuentran en Estados Unidos y no han retornado. Sin embargo, la juventud retornada no tiene la identidad del migrante que se quedó. Ella tiene en su tesoro de aventuras la decisión del retorno (no sólo la añoranza), la cual le da una perspectiva distinta.

La decisión del retorno voluntario supone una valoración de lo que es Guatemala (o Zacualpa) y lo que son los Estados Unidos. En el proceso de valoración esa juventud descubre que los Estados Unidos no son sólo un país donde abunda el dinero, sino que son, con palabras de un joven, "una realidad muy fea", donde los millonarios se suicidan, se derrocha la comida en los restaurantes, el trabajo esclaviza, la discriminación está instituida en toda la estructura social. También descubre que Guatemala, a pesar de su pobreza y la suciedad de sus calles y muchas lacras que le chocan al volver, ofrece oportunidades para vivir "con humildad", con felicidad y tranquilidad, con las satisfacciones insustituibles de la familia, la belleza del lugar y el sentido de la autoestima. Estas son palabras casi textuales de un joven adulto medio filósofo que retornó, no por tener un mal trabajo, sino por opción de estar con su esposa e hija.

¿De dónde encontramos que nace la opción del retorno? Según este joven, nace de un proceso de autovaloración que ha acompañado al proceso de valoración de Guatemala. Es un proceso empapado de experiencia, que la juventud ha vivido cuando estaba por cortar la identidad de origen a través de una fuerte crisis o cuando sufre la crisis de la imposibilidad de adaptarse a la comunidad de migrantes en los Estados Unidos. Este proceso de autovaloración parece que tiene dos extremos de donde se vive: uno, del exceso de relaciones de experiencia que lo enraízan en el norte (enamoramiento, por ejemplo) o de la falta de esas relaciones que la mantienen como una extraña que continuamente piensa en sus hijas hasta que por fin retorna. En el contraste de nuestros casos, el primer extremo es más propio de los varones y el segundo de las mujeres. Recordemos, sin embargo, que estamos siempre en el terreno hipotético.

Nos parece que estos procesos de valoración y autovaloración son los que construyen las bases del (posible) liderazgo de la juventud retornada. ¿Por qué? Encontramos cuatro razones principales. Primero, porque la valoración implica una posibilidad objetiva de vivir dignamente (aunque sea "humildemente") en la comunidad y país de origen. Es decir, supone que esa juventud retornada tiene recursos, oportunidades de trabajo y cierto poder económico para salir adelante en Guatemala. Alguien que se va a morir de hambre en Guatemala difícilmente opta por volver. Segundo, porque esa juventud tiene un elemento subjetivo por el que esa posibilidad objetiva se le convierte en realidad para ella misma: es la confianza de que mejorará su vida en el lugar de origen. Sin esa confianza, muy emparentada a la autoestima y a la autovaloración, el retorno se le hará negro y cuesta abajo hacia un fracaso, aunque tenga la posibilidad objetiva. Tercero, porque esta juventud que retorna se sabe partícipe de una historia colectiva de millones de personas que han migrado, aunque no retornen. Esa conciencia e identificación le da la sensación 
de pertenecer a una etapa de la historia y a un pueblo que sufre y lucha como si fuera una revolución universal. Tal vez no lo dice así, pero su imaginario ha cambiado completamente de lo que podía haber sido el imaginario colectivo de los años ochenta en que el heroísmo se relacionaba con la sobrevivencia de las grandes masacres y la revolución. Ahora es otra cosa. Esta juventud está consciente de estar participando de un río humano que invade el país más poderoso de la tierra. Esto le da fuerza. Y cuarto, esta juventud trae al lugar de origen nuevos conocimientos tecnológicos, destrezas aprendidas, visiones más amplias, tal vez otro idioma. Pero ante todo, lo que más fuerza le da es el descubrimiento comparativo del aquí y del allá y el descubrimiento de sí misma en la crisis de identidad que vivió o en la falta de adaptación que la hizo sufrir. Por eso, su palabra se respeta y su apoyo se aprecia, aunque también se resiente como amenaza y se puede mirar como señal de orgullo.

Sabemos que estamos idealizando un poco las cosas, pero nos han influido las palabras de la juventud con que hablamos. El filósofo decía que hay juventud retornada que se cree la gran cosa y exagera las historias que vivió en el norte, pero que también hay juventud retornada que se desviste de las señales de prestigio que trae, porque lo que desea es de verdad sumirse en su comunidad, identificarse con ella, retornar profundamente y ser aceptada a pesar de que venga del norte. Nos llamaba la atención, por ejemplo, cómo la joven con quien hablamos contaba que tardó un mes en presentarse en público porque volvía muy blanca y se quería quemar un poco la piel. El joven diría que todo depende de la autoestima para que el retorno sea verdadero.

\section{Capacidad de liderazgo político}

Aunque esta juventud adulta vivió de niña la persecución y las masacres, huyendo a las fincas, y experimentó la pobreza extrema antes de emigrar al norte, esta experiencia, como hemos dicho, no se encuentra en el centro de su imaginario, como se encuentra en sus padres que narran los horrores vividos. Para esta juventud la hazaña del norte focaliza las aventuras heroicas, siendo el paso del desierto, como la puerta de entrada, no sólo a los Estados Unidos, sino a todas sus narraciones.

Pero no ha sido todo dolor. Ha experimentado, aunque no la haya gozado plenamente, la afluencia de los Estados Unidos, y al retornar la compara con la de su pueblo y le choca la situación de pobreza de Zacualpa. Entonces le nacen inquietudes por mejorarla, aunque muchas de ellas se quedan en planes y puras palabras. Esas inquietudes no nacen desde la pobreza, sino de la conciencia de clase emergente a la que pertenece ya. Pero no trae experiencia política para encauzar esta inquietud y fácilmente se dispersa en esfuerzos individuales para metas que no son del bien realmente común o claudica ante la dificultad de la empresa.

En el norte, por su destitución legal, tampoco tuvo experiencias de enfrentamiento con autoridades o patronos. Está acostumbrada a una práctica de diálogo subordinado. Al retornar, sin embargo, el contexto legal es otro y vuelve a ser ciudadana. Entonces, el diálogo al que está acostumbrada deja de ser subordinado y puede pasar al enfrentamiento.

¿Pero ante quién va a luchar? ¿Cuáles son sus amenazas? Hemos encontrado dos principales. La primera es la violencia común. Contra ella se inclina entonces a oponerse, concentrando 
su atención en la juventud más joven, por un lado, y en la ausencia de ley y orden, por otro. Allí es donde ya en Zacualpa idealiza un aspecto del sistema norteamericano: la ley. La idealiza, aunque ella misma la violó permanentemente y aunque decidió volver a su tierra porque había descubierto que Estados Unidos es "una realidad muy fea". Por eso, esta juventud se inclina a ser partidaria de la mano dura, por proteger, como dijimos arriba, sus bienes y sus hijos pequeños.

Otra amenaza más lejana que siente en el horizonte es la deportación de los emigrantes. Aunque es juventud retornada, no favorece que muchos, ni menos todos, vuelvan: "nos comeríamos unos a otros". Por la competencia de muchos contra muchos le estorbarían el negocio, el espacio de empleos, las decisiones y el poder. ¿Pero qué hacer en Zacualpa o Guatemala para presionar al gobierno de allá? No ve qué. Las comunidades transnacionales no dejan de encontrarse divididas por los límites de los Estados nacionales.

Y la pobreza de Zacualpa, ¿̇no es una amenaza para esta juventud? ¿Hay formas de resolverla? Según su experiencia, la poca riqueza que tiene Zacualpa ahora le ha venido del norte. Entonces, según ella, la solución debe venir de fuera. El modelo de la entrada de riqueza ha sido la divisa. Se manda de allá, pero se administra aquí. Es un modelo que lleva tensión y la juventud retornada la conoce perfectamente. Entonces, no puede tampoco venir toda la solución de allá. Si se envían remesas colectivas, por ejemplo, (en Zacualpa no hemos encontrado que se haya dado ese paso) para proyectos comunales, esa juventud puede servir de puente para canalizarlas, evitando que todo se decida en el norte, y para administrarlas evitando la desconfianza de la comunidad local. Y lo que se dice de remesas económicas puede trasladarse a remesas sociales y remesas políticas.

Esta juventud retornada ha venido destituida de una experiencia política del norte, pero no se puede descartar que tenga luego un liderazgo político que de alguna manera reciba fuerza de allá (por ejemplo, del movimiento de migrantes) y la encauce aquí. ${ }^{8}$ El hecho de que en el período electoral pasado el candidato más importante de la oposición para la alcaldía de Zacualpa fuera un retornado adulto del sector ladino de la ciudad indica que nada impide que también un hombre o una mujer retornada indígena pueda serlo. Se trata de juventud abierta al aprendizaje, como esponja, y una juventud que ha vivido de cerca el sistema de explotación global y conoce sus debilidades. Es una juventud que al entrar en la arena política sabrá centrarse mejor en esta época de la globalización y en las inmensas posibilidades de las identidades que la globalización misma suscita y se le vuelven en contra.

\section{Relación de género}

Para un varón entrado en años que no ha tenido formación en el terreno de género, como un servidor, al entrar en este terreno lo hace de puntillas. Con esta salvedad, intentamos concluir un par de cosas sobre la juventud retornada y la relación de género.

No podemos ocultar que la migración indígena en Zacualpa expresa el patriarcado. El patriarcado no respeta las diferencias étnicas. Está también instalado en la cultura indígena. Según el patriarcado, el hombre es para la calle (el norte) y la mujer es para la casa (la patria). Alrededor del 16\% de la población que emigra es femenina. 
Por el mismo patriarcado -es nuestra hipótesis- el retorno es más propio de las mujeres que de los varones. Alrededor del $24 \%$ de la población migrante retornada del casco urbano es femenina.

La relación entre hombre y mujer, originada más frecuentemente por la migración, es la del varón que sale y manda remesas desde los Estados Unidos y la mujer que se queda y las administra en la comunidad. El varón que retorna, en este caso típico, retorna al hogar de la mujer que no ha migrado. Esta juventud masculina retorna con la experiencia de haber vivido casi como soltera en los Estados Unidos, con compañeros de trabajo y de vivienda varones. Trae en su boca una historia que suele invisibilizar la relación con otras mujeres allá, a no ser que esté dispuesta a contar de su rica y aventurada vida privada. En los relatos de nuestras entrevistas mencionaron a las mujeres muy de paso: la viajera por el desierto, la supervisora, la mujer policía, etc. Por el contrario, esta juventud masculina destaca la relación desde el norte con las mujeres de su hogar en Zacualpa, la madre, la novia, la esposa, las hijas. Ellas son su principal polo de referencia en la comunidad.

Pero hemos encontrado entre nuestros entrevistados que ellos son muy conscientes del contraste de género que existe entre la situación de la mujer que está en Zacualpa, controlada socialmente por mil ojos que la siguen y mil lenguas que hablan de ella, y la situación del hombre que está en el norte, quien goza de libertad de movimiento y no tiene casi control social: para él “todo se vale”. La relación de estos jóvenes adultos con sus esposas en Zacualpa suele entrar, entonces, en crisis por el tipo de relaciones de experiencia que viven en los Estados Unidos. La solución de la crisis a favor de la esposa es un ingrediente importante para el descubrimiento de su propio yo íntimamente unido a la valoración a favor de Guatemala. Descubre el verdadero amor, se descubre a sí mismo y descubre a Guatemala. Este proceso, que tampoco puede idealizarse, unido al control social en Zacualpa, dará por resultado la tendencia a una relación de género más equilibrada, cuando él retorna, aunque la inversión en casa, terreno, negocio, riego, carro... haya provenido exclusivamente de su trabajo en Estados Unidos (no del trabajo de ella) y lo coloque en un nivel de mucho poder frente a ella.

En cuanto al menor número de mujeres jóvenes retornadas, éstas suelen ubicarse en el tipo que incluye a mujeres que han migrado con sus maridos o siguiéndolos y que después retornan, ya sea antes que sus esposos, ya sea con ellos. Sobre ellas versan estas conclusiones hipotéticas.

Esa juventud femenina que ha estado en los Estados Unidos ha pasado en el norte por la experiencia agotadora de un trabajo que apenas le da tiempo para descansar. Si va como doméstica o como empleada de limpieza, por ejemplo, su trabajo no tiene nada que ver con el trabajo de ama de casa que desempeñó en Zacualpa. Ese trabajo, sin embargo, le permite igualdad económica frente al marido allá y puede entrar así en una nueva relación de amor que le va transformando el modelo de mujer que traerá al regresar a la comunidad. Comprueba también que es posible ser esposa sin tener hijos. Los hijos que ha dejado en Guatemala siguen siendo su polo de referencia y la jalonan más a ella que a él, por el patriarcado mismo. Entonces, cuando retorna, esta joven adulta proyecta en los hijos, sobre todo en las niñas, la imagen de lo que ella no pudo ser como mujer y como esposa. De allí que el patriarcado se vaya erosionando generacionalmente. 
Cuando ella retorna, la relación transnacional con el esposo se mantiene y ella participa en una empresa familiar en la que él manda las divisas y ella las administra. En esta relación, ella se diferencia de las esposas que no han viajado al norte (viudas blancas) y reciben la remesa del marido, porque ella ya tuvo la experiencia de vivir y trabajar en los Estados Unidos y la casa, o el terreno o el agua potable, o el negocio son producto, al menos parcial del trabajo de ella en el norte. Esas inversiones no son sólo del esposo que está allá, sino de ella también. Entonces, el esposo en su regateo económico por teléfono no la puede fácilmente engañar, ni hacerla depender de su autoridad como si estuviera vendada de los ojos.

Esta relación a distancia no deja de ser tensa, pero ella prefiere el diálogo al enfrentamiento, pues el pleito podría afectarla a ella y a los hijos dejándola sin la remesa. Por otro lado, dicha relación le da liderazgo público en la comunidad, porque la gente sabe que tiene conexión con el norte. Pero ese liderazgo se basa también en la valentía que le ha dado la experiencia del norte donde ha aprendido a moverse en espacios implícitamente prohibidos a la gente indígena en Guatemala, especialmente a las mujeres, como restaurantes, oficinas públicas, bancos, y en espacios machistas (calles donde se juntan jóvenes varones) que ella ya no teme atravesar aunque le digan cualquier semipiropo ofensivo. También trae la valentía para enfrentarse a la autoridad masculina, aunque sea de más edad, si se trata de la defensa de sus hijos.

Cuando el esposo retorna más tarde, esta mujer retornada sufre un recorte de su autoridad y de la iniciativa para planes de superación económica que arreglaba en la ausencia de él. Se le recortan también los planes de educación para sus hijos. Si ella insiste en que a las hijas hay que darles educación a toda costa para que dejen de quemarse la cara frente al fogón, él se mostrará más resistente para hacer este sacrificio, aduciendo sus limitaciones económicas, y preferirá que se empleen como domésticas de hogares más ricos, ya sea en el municipio o en la capital del país. Nada más opuesto al ideal de ella, que antes de migrar a los Estados Unidos fue también migrante interna en el territorio guatemalteco y por eso se quedó sin la educación que le abre puertas para un empleo mejor remunerado.

Las nuevas y múltiples formas de hogares de mujeres que tienen esposos en Estados Unidos se vinculan con otras formas de hogares donde, por ejemplo, un hermano o una hermana están en el exterior. Se vinculan con hogares de la misma familia extensa que viven en pueblos vecinos a Zacualpa o en otros lugares de Guatemala. El hogar de los padres adultos en Zacualpa suele ser, entonces, el centro de esta verdadera telaraña de mujeres (hermanas o cuñadas) que se apoyan horizontalmente entre sí y que expresan la suerte de tener parientes íntimos en el norte en fiestas religiosas, de cumpleaños o inauguraciones de casas. Son momentos en que ellas se experimentan con poder, aunque esas fiestas sean posibilitadas por el dinero de los parientes varones desde Estados Unidos, cosa que se hace sentir por las llamadas telefónicas continuas, apenas audibles en el trueno de los instrumentos electrónicos. Algunas pocas de estas mujeres pueden ser retornadas, otras no.

Dentro de estos hogares con parientes en Estados Unidos van apareciendo a veces las clases sociales entre las dueñas de los hogares y las domésticas traídas de la montaña, es decir, de 
aldeas apartadas del mismo municipio o de municipios vecinos. El trabajo doméstico del que la mujer se liberó al regresar del norte se reproduce, siendo ella la patrona.

\section{Clase emergente}

La juventud adulta retornada es un sector social doblemente emprendedor porque tiene la doble experiencia de haberse arriesgado a buscar un sueño en el norte y de haberse arriesgado a reintegrarse en su pueblo.

Allá experimentó los trabajos peor pagados y más despreciados, el ritmo exigente de la jornada diaria (a veces doble), la debilidad de la negociación (por ser ilegal) frente a los patronos y muchas otras cosas que aparecen en los temas recurrentes de las historias. En la experiencia de la dureza del trabajo vio muchas veces retratado, como en un miniespejo, lo que son los Estados Unidos.

Pero allá también experimentó el ascenso laboral, el agrado de muchos patronos con su comportamiento y cierto éxito económico que muchas veces fue el principio de "vicios", accidentes, la pérdida misma del empleo y de otros papeles, como licencia de conducir, que le eran necesarios para trabajar. El relativo éxito económico, en comparación con otra juventud que no ahorró, le dio perspectivas abiertas de inversión en Zacualpa. Si no hubiera tenido esas perspectivas, no hubiera vuelto.

Pero al retornar, ya no pertenece a la clase campesina del municipio. Comienza a ver de lejos a los pobres, especialmente a los pobres de las aldeas. Ha dado un salto cualitativo, aunque pequeño. A su vez esta juventud adulta es vista por la gente pobre como si ya se hubiera olvidado del sufrimiento de su familia y de la pobreza de su origen. Pero esta juventud dice que no se ha olvidado y argumenta a partir de ese mismo sufrimiento para enaltecer su propio esfuerzo.

No se siente amenazada por las clases pobres, a las que considera sumisas y bastante desvalidas, incluso dignas de compasión. Se siente amenazada por la juventud más joven que se organiza en grupos callejeros y puede tener contacto con maras externas más fuertes. La amenaza puede venir contra el negocio, carro y casa, y contra los hijos, que si son varones pueden integrarse en esos grupos, y si son mujeres pueden ser abusadas e incluso violadas. La amenaza se vive con ambigüedad, porque en el caso de los jóvenes retornados, ellos mismos estuvieron en los bordes de esos grupos y los conocen de cerca. Pero todos, jóvenes retornados y retornadas, se valen del conocimiento de los hábitos juveniles callejeros para defenderse.

Debemos distinguir a la juventud adulta retornada de una clase social más adinerada, más estable, más adulta y más reducida. La primera pertenece en su mayoría a un sector que ha emergido de la pobreza y está en transición hacia consolidarse como clase social más identificada con la segunda o hacia volverse a empobrecer o a estancarse en su medianía. La segunda está compuesta por gente adulta retornada o no retornada y tiene, entre algunos de sus miembros, amarre con el negocio del coyotaje y, según se comenta, con el narcotráfico u otros poderes ocultos. Cuando hablamos de la capacidad de transformación de la juventud adulta retornada no nos estamos refiriendo a la segunda. 
Además, hay que insistir que esa juventud retornada es sólo un elemento pequeño de la clase media emergente, generada en gran parte por las remesas del norte, pero no únicamente por esas razones.

\section{Alianzas interétnicas}

La identidad étnica de la juventud retornada indígena no se discute. iRetornó a su pueblo! El retorno supone el afianzamiento de una identificación con Zacualpa, con la familia, madre, padre, esposa, hijos, todos ellos indiscutiblemente indígenas.

En esta juventud no ha habido pérdida de identidad, aunque sí una erosión grande de muchos elementos culturales que desde fuera pueden ser considerados como señales de identidad. Se da, entonces, una contradicción de miradas y de opiniones. Una cosa es oír a esta juventud adulta retornada hablando sobre lo que siente ella misma y otra oír a quienes no salieron al norte.

En el norte se le rompió el paradigma bipolar ladino indígena, pues fue identificada como migrante o hispana, es decir, se la revolvió a ella en una misma identidad (adscrita), donde caben mestizos, ladinos, mexicanos... También fue identificada como guatemalteca y ella misma prefirió muchas veces autonombrarse como guatemalteca, no como zacualpense, ni indígena, porque Guatemala suena más que Zacualpa en Estados Unidos. ${ }^{9}$

Sin embargo, hay otro paradigma también bipolar que ella no conocía y experimentó. Este paradigma es el que distingue al "ilegal" (casi igual a "emigrante") del "legal" dentro de un sistema de discriminación complejo, en el que el ilegal es la víctima más baja que recibe el peso de la discriminación de otras poblaciones también discriminadas, como la guatemalteca residente o la chicana. Los testimonios son muy claros en este respecto. El chicano o la guatemalteca residente han aprendido a repetir hacia el emigrante "ilegal" la discriminación que han sufrido y siguen sufriendo. En este sistema, las fibras raciales se entretejen con las económicas, las sociales, las legales, a veces coincidiendo, a veces no. No parece sencillo analizarlo, menos desde lejos. Sin embargo, en el fondo vemos que se repite la bipolaridad (los millones que viven "en la sombra" y los que están en la claridad) y la juventud retornada trae la experiencia de haberla vivido constantemente. ${ }^{10}$

Pero cuando esta juventud retorna y en su tierra vuelve a ser "legal" le resulta muy fácil relacionarse con la población ladina de su pueblo con la cual comparte una misma posición de clase frente al campesinado indígena. Entonces, dentro de la misma etnia aparece una discriminación social entre indígenas de aldea e indígenas de la ciudad, la cual a su vez provoca migración de las aldeas al casco urbano y tiende a fortalecer la desigualdad. Allí es donde se genera esa doble mirada, la propia, la de la juventud retornada que se afirma indígena, y la externa a ella, especialmente de la gente rural, que considera que esa juventud ya cambió de "pensamiento" y se volvió ladina, tanto más que el aspecto externo (incluso la piel) se va asemejando al del ladino. Entonces aparecen sutiles discriminaciones raciales -no sólo de clase- internas a la etnia, cosa que la juventud retornada consciente (es decir, la que tiene una autoestima bien fundada) vive con mucha sensibilidad y podría ser el motor hacia una mayanización más amplia a base de personas con experiencia no rural. Si 
dijéramos que el proceso de mayanización es como una flor que se va abriendo, en Zacualpa todavía no se ha abierto, aunque los brotes de esas flores están allí y sólo requieren un contexto más favorable de formación y organización. ${ }^{11}$

\section{Religión sicologista}

La migración al norte no se vive como pecado. Más aún, en medio del brillo del consumismo, se encuentra con frecuencia una atracción del norte a la que las historias le dan rasgos religiosos, como si esa migración hubiera sido una llamada de Dios. ${ }^{12}$

La juventud migrante tiene una religiosidad mamada en los hogares. Luego, aunque ella se olvide de practicarla en público por la falta de tiempo ("aquí vinimos a trabajar") o por las relaciones de descanso agitado (trago, drogas y otros "vicios") o por otra razón, esta religiosidad resurge como fuego entre cenizas en las crisis de identidad, en el sufrimiento de la no adaptación o en el debate interno entre quedarse o volver, entre tomar una nueva compañera o volver a la esposa. Se trata de expresiones religiosas no culturales (misa o servicios) y no institucionales (iglesia), que, sin embargo, a veces impulsan a buscar la iglesia. Cuando se llega a dar una relación institucional, ésta puede impedir el retorno, al contribuir a generar la identidad de allá.

$\mathrm{Al}$ retornar, esta juventud tiende a reintegrarse en las redes de iglesia que son mediación para la aceptación de la comunidad. Entonces, desarticula la participación religiosa externa, no convencida, que tuvo en el norte, de otras actividades de descanso. La socialización de los hijos en la familia le exige también educarlos religiosamente y dar el ejemplo con la práctica. La integración en la iglesia puede ser intensa, aunque tendiente a las manifestaciones exclusivas de espacios religiosos (cantos, celebraciones, sacramentos, cultos, fiestas) sin conexión con la justicia. Las interpretaciones religiosas tienden a ser más intimistas y sicologistas, y menos sociales. Es lo que está en el ambiente. Mucha plática sobre autoestima y poco sobre justicia social. Sin embargo, como religiosidad de clase emergente, en vaivén, mirando para arriba y mirando para abajo, así como puede fortalecer la ideología del trabajo, del ahorro, de la bondad y bendición de la riqueza, de la clase escogida por Dios, así puede también fortalecer una concientización de las causas estructurales de la pobreza y una búsqueda de formas organizadas para superarlas. Para esto hace falta formación, relaciones de experiencia hacia la justicia, y organización, aunque sea de pocas personas. Como esto es difícil, la tendencia será que la religiosidad emergente legitime el status quo.

Todo lo cual nos deja en la última conclusión que ya mencionamos arriba: inecesita formación política! No aisladamente, puesto que ella rechaza la identidad de retornada -aunque lleve el aura que decíamos arriba de haber estado en el norte-, sino en unión con otra juventud adulta sedienta de conocimientos y de orientación para la transformación de la comunidad y del país en una etapa de globalización. 


\section{Repetimos al final...}

... lo que dijimos al principio. Estamos en un mundo de rápidos cambios. El ambiente de hace un año cuando se terminó el libro que aquí resumimos era distinto del que estamos hoy viviendo. Y el de hace un año también distinto del que vivieron los informantes cuando retornaron voluntariamente a Guatemala. En la actualidad el ambiente del norte se está haciendo cada vez más hostil para la población migrante, no sólo por las deportaciones, cada vez más numerosas, sino por la recesión económica. Todo esto se nota en la desaceleración del ascenso en el monto de las remesas: 19\% entre 2000 y 2006 y $6 \%$ entre 2006 y 2007 , según cifras recientes del Banco Mundial.

El enrarecimiento del ambiente en el norte respecto a la población migrante tiene dos repercusiones en el tratamiento de la migración. Primera, que cada vez se hará más importante el tema de la migración retornada, pues se espera que cada vez habrá más población retornada "voluntaria" (no deportada). ${ }^{13} \mathrm{Y}$ segunda, que estaremos ante un retorno voluntario/forzado, más del tipo intermedio entre el voluntario y el forzado que ante

124 un retorno voluntario, que ha sido el tema de este artículo. El análisis se va desplazando según se mueve la coyuntura.

\section{Notas}

1 Afines de abril 2008, mientras terminamos este artículo, ha salido ya de la imprenta el libro intitulado Migración transnacional retornada. Juventud indígena de Zacualpa, Guatemala.

2 En 1985 el quetzal estaba a 2.67 por un dólar; en 1990, a 4.95; y en 1995, a 6.03.

3 SJM-CA: Servicio Jesuita para Migrantes, Centro América. Se trata de una red de obras de la Compañía de Jesús que intentan responder al reto de la migración desde la investigación, la incidencia política y la pastoral en CA. Esta red se une a otras del flujo norte: SJM México, SJM Norteamérica, etc.

4 Dice un autor que "la migración retornada es el gran capítulo que está por escribirse en la historia de la migración" (King 2000:7).

5 Para Guatemala: se ha estudiado el retorno colectivo de refugiados guatemaltecos de México, incluso jóvenes (North y Simmons 1999; Hurtado 2002; Falla 2005; Falla 2006; Mateo y Camus 2007, entre otros), pero no el retorno individual desde Estados Unidos, aunque en muchas monografias y artículos se hace referencia a casos de personas retornadas. La excepción es un estudio sobre el deseo de retornar de guatemaltecos/as y salvadoreños/as de Phoenix, Arizona (MoranTaylor y Menjívar 2005). Para El Salvador: el magnífico Informe sobre Desarrollo Humano de ese país (PNUD 2006), al mencionar la inmigración hacia El Salvador, sólo toca sistemáticamente el caso de "los deportados" y el de la migración desde otros países de CA (p. 40 - 45), no el de la migración retornada (voluntaria), aunque se supone su influjo político (p. 256, p. 261).

6 Según Castells, la sociedad en red es la forma de organización propia de la globalización. De los tres volúmenes de su obra, el primero está dedicado a este tema. (Castells 2001).

7 Estudiando el Popol Wuj vemos el caso de la princesa Ixkik', nacida de padres de Xibalbá pero migrada a los reinos de la superficie del mundo. ¿De dónde se siente ella? Nunca puede negar que es xibalbeña. Su nombre mismo lo dice, porque en ese término aparece la raíz kik' que quiere decir, sangre. Ella es del reino del miedo, de la violencia y de la muerte. Pero su opción ha sido por los reinos de la superficie del mundo, no porque allí se sienta ella más aceptada, ya que la abuela de los héroes la desprecia, sino porque tiene la identidad de una misión que es la de dar a luz y criar a los héroes que derrotarán las tinieblas.

8 Quizás la que venga con las experiencias de las grandes manifestaciones de migrantes en Estados Unidos a partir de 2006 venga distinta.

9 Depende de contextos. Si hay mucha población de un pueblo o de un área lingüística (q'anjob'al) en una ciudad de Estados Unidos y tienen organizaciones visibles, entonces es más fácil ostentar la identidad local que la nacional, por ejemplo en 
Los Ángeles (Popkin 1998) y Jupiter, Florida (Palma, Girón y Steigenga 2007). Compárese, por el contrario, con Phoenix, Arizona (Moran-Taylor y Menjívar 2005) e Immokalee (Williams 2005), donde la población guatemalteca se encuentra muy revuelta y es dispersa o estacional. En el caso de Zacualpa, la concentración más mencionada se da en Providence, Rhode Island, pero allí hay tanto población ladina como indígena de Zacualpa.

10 Al hablar de la reforma migratoria, el siguiente autor maneja a la población "ilegal" como si estuviera en la sombra. La reforma permitiría "a los inmigrantes ilegales que ya están aquí [en Estados Unidos] obtener su salida de la sombra" (Jacoby 2006: 61).

11 Para ver un proceso de mayanización q'anjob’al apoyado por la iglesia católica en los Estados Unidos, véase (Popkin 1998).

12 Recordemos a Abraham que fue llamado por Dios a salir de Ur, según el Génesis $(12,1)$.

13 Véase el flujo de retorno fuerte de migrantes brasileños desde Estados Unidos iniciado ya en 2007 por razones económicas (Bernstein y Dwoskin 2007).

\section{Referencias bibliográficas}

BERNSTEIN, N. \& DWOSKIN, E. (2007, 4 de diciembre) “Giving up their American Dream”. New York Times.

CAMUS, M. (ed.) (2007) Comunidades en movimiento: la migración internacional en el norte de Huehuetenango. Guatemala: Instituto centroamericano de Desarrollo y Estudios Sociales (INCEDES) y Centro de Documentación de la Frontera Occidental de Guatemala (CEDFOG).

CASTELLS, M. (2001) La era de la información. Economía, Sociedad y Cultura. Vol. I: La sociedad red. Vol. II: El poder de la identidad. Vol. III: Fin de Milenio. México: Siglo 21. (1 ${ }^{\mathrm{a}}$. Edición en inglés: 1996).

CONWAY, D. \& POTTER, R. B. (2007) "Caribbean Transnational Return Migrants as Agents of Change".En Geography Compass. Vol. 1, No. 1, pp. 25.45.

FALLA, R. (2005) Alicia. Explorando la identidad de una joven maya. Ixcán, Guatemala: Avancso y Editorial USAC. (2006) Juventud de una comunidad maya. Ixcán, Guatemala: Avancso y Editorial USAC. (2008) Migración transnacional retornada. Juventud indígena de Zacualpa, Guatemala. Guatemala: Avaneso y Editorial USAC.

HURTADO PAZ Y PAZ, M. (2002) "Aquí estamos esperándolos". Vivencias de mujeres retornadas esposas de trabajadores migrantes en los Estados Unidos. Caso de la Colonia 15 de octubre, La Trinidad, Escuintla, a tres años de su retorno a Guatemala. Guatemala: Universidad de las Regiones Autónomas de la Costa Caribe Nicaragüense, URACCAN y Escuela Superior de Educación Integral Rural, ESEDIR.

JACOBY, T. (2006) "Immigration Nation”. En Foreign Affairs (Nov/Dic.), Council on Foreign Relations, Vol. 85, No. 6.

KING, R. (2000) "Generalizations from the history of return migration" (pp. 7-56). En: Gosh, B. (ed.) Return migration: Journey of hope or despair. Geneva, Switzerland: International Organization for Migration and the United Nations. Pp. 7-56.

MATEO, M. \& CAMUS, M. (2007) "Una mujerq’anjob'al de Mamá Maquín"pp.119-150. En Camus, M. (ed.) (2007) Comunidades en movimiento: la migración internacional en el norte de Huehuetenango. Guatemala: Instituto centroamericano de Desarrollo y Estudios Sociales (INCEDES) y Centro de Documentación de la Frontera Occidental de Guatemala (CEDFOG). 
MORAN-TAYLOR, M. \& MENJÍVAR, C. (2005) Unpacking Longings to Return: Guatemalans and Salvadorans in Phoenix, Arizona. International Migration. Phoenix Arizona. Mimeo.

NORTH, L. L. \& SIMMONS, A. B. (1999) Journeys of Fear. Refugee Return and National Transformation in Guatemala. Canadá: Mc Gill Queen's.

PALMA, S. I., GIRÓN, C. \& STEIGENGA, T. J. (2007) "De Jacaltenango a Jupiter: negociando el concepto de familia en el espacio transnacional y el tiempo" (171-204). En Camus, M. (ed.) (2007) Comunidades en movimiento: la migración internacional en el norte de Huehuetenango. Guatemala: Instituto centroamericano de Desarrollo y Estudios Sociales (INCEDES) y Centro de Documentación de la Frontera Occidental de Guatemala (CEDFOG).

PNUD (2006) "Una mirada al nuevo nosotros. El impacto de las migraciones". Informe Nacional de Desarrollo Humano, San Salvador.

POPKIN, E. S. (1998) In Search of the Quetzal: Guatemalan Mayan Transnational Migration and Ethnic Identity Formation. University of California, Los Angeles: UMI Company.

WILLIAMS, P. J. (2005) "Looking for Lived Religion in Immokalee, Florida". Programa CIESAS Peninsular. Florida. Presentación a la Conferencia auspiciada por la Fundación Ford: Latinos in Florida: Lived Religion, Space and Power. Antigua, Guatemala. 